\title{
Investigating Cybercrimes In Malaysia: The Importance Of E- Commerce Security To Eliminate Fraud And Security
}

\author{
INTAN MAIZURA ABD RASHID ${ }^{1}$ \\ UNIVERSITI TEKNOLOGI MARA, ALOR GAJAH, MELAKA, MALAYSIA \\ intanmaizuraar@gmail.com \\ WAN SALLHA YUSOFF ${ }^{2}$ \\ UNIVERSITI MALAYSIA PERLIS, MALAYSIA \\ SURAIYA IBRAHIM ${ }^{3}$ \\ UNIVERSITI MALAYSIA PERLIS, MALAYSIA \\ SAYANG NURSHAHRIZLEEN RAMLAN ${ }^{4}$ \\ UNIVERSITI MALAYSIA PERLIS, MALAYSIA \\ IRZA HANIE ABU SAMAH ${ }^{5}$ \\ UNIVERSITI TEKNOLOGI MALAYSIA, MALAYSIA
}

\begin{abstract}
The e-commerce marketplace in Malaysia is showing an advantageous trend, with gross value added contributed $6.3 \%$ to gross domestic product (GDP) in 2017. Online purchasing has attained a lot of important factors in the current marketing. But, because of the number of growth of trouble makers or scams had increased, such activities will create a fear in the mind of customers and as well can influence the attitude or mind set of consumers toward online purchase. Therefore, the issue in this area of this survey is customer's dissatisfaction and attitudes towards online purchasing.Apart from that, customers also concern about the security level whenever they order products online. The security refers to online transaction safety. The previous researchers suggest that the lack of security on the website will make the customers to have doubt or serious concern about their credit card transactions and privacy of personal information to avoid cybercrimes.In spite of comfort and advantages of online shopping, e-commerce poses a few demanding situations and concerns amongst consumers on security and privateness problems. Thus, this phase intends to identify degree of situation in regards to these issues. In widespread, slightly extra than half of on-line buyers claimed that they are problem on safety and privacy at the same time as buying online. The regression analysis indicates fraud and security was found to have significant at $5 \%$ significant level (sig, $t=0.004$ ). This could explained that customers are more likely to take serious on fraud and security of the products they purchased.
\end{abstract}

Key words and phrases.-E-Commerce Security, Cybercrimes, Customer Dissatisfaction, Malaysia, Fraud \& Security, Online Purchasing 


\section{INTRODUCTION}

On-line income services from e-commerce firms have the capability of essentially converting the way consumers buy items and services. It covers the troubles concerning safety and privateness at the same time as doing on-line transactions. But, the capacity of e-commerce has now not been fulfilled due to purchasers "e perceptions of the dangers concerned in engaging in enterprise on-line. There are numerous literature to show that the technological factors in e-commerce that specialize in protection and privateness are safe and sound however the purchasers still understand that they may be not enough and show dissatisfaction.

\section{METHODOLOGY}

Table 1 shows the sample profile of the questionnaires survey. A total of 375 questionnaires were distributed among randomly selected respondents. However, only 300 questionnaires were successfully collected and used for analysis in the present research. Therefore, only 300 of total questionnaires distributed were satisfactorily completed and tested by using the Statistical Package for Social Science (SPSS) software.

\begin{tabular}{|l|l|}
\hline Number of questionnaires distributed & 375 \\
\hline Number of questionnaires collected back & 300 \\
\hline Response rate & $80 \%$ \\
\hline Number of questionnaires used for analysis & 300 \\
\hline
\end{tabular}

Table 1 Sample profile of survey

Sampling Method

\begin{tabular}{|c|c|c|c|}
\hline Variables & Categories & Frequency & $\begin{array}{l}\text { Percentage } \\
(\%)\end{array}$ \\
\hline Gender & $\begin{array}{l}\text { Male } \\
\text { Female }\end{array}$ & $\begin{array}{l}112 \\
188\end{array}$ & $\begin{array}{l}37.3 \% \\
62.7 \%\end{array}$ \\
\hline Age & $\begin{array}{l}\leq 18 \text { years old } \\
19 \text { to } 22 \text { years old } \\
23 \text { to } 25 \text { years old }\end{array}$ & $\begin{array}{l}113 \\
104 \\
83\end{array}$ & $\begin{array}{l}37.7 \% \\
34.7 \% \\
27.7 \%\end{array}$ \\
\hline Race & $\begin{array}{l}\text { Malay } \\
\text { Chinese } \\
\text { Indian }\end{array}$ & $\begin{array}{l}239 \\
40 \\
21 \\
\end{array}$ & $\begin{array}{l}79.7 \% \\
13.3 \% \\
7.0 \% \\
\end{array}$ \\
\hline $\begin{array}{l}\text { Profession } \\
\text { Occupation }\end{array}$ & $\begin{array}{l}\text { Unemployed } \\
\text { Employed } \\
\text { Students }\end{array}$ & $\begin{array}{l}101 \\
94 \\
105\end{array}$ & $\begin{array}{l}33.7 \% \\
31.3 \% \\
35.0 \%\end{array}$ \\
\hline $\begin{array}{l}\text { Time spend on } \\
\text { internet per day }\end{array}$ & $\begin{array}{l}1-5 \text { hours } \\
5-10 \text { hours } \\
\text { More than } 10 \text { hours }\end{array}$ & $\begin{array}{l}214 \\
72 \\
14 \\
\end{array}$ & $\begin{array}{l}71.3 \% \\
24.0 \% \\
4.7 \% \\
\end{array}$ \\
\hline Tools & $\begin{array}{l}\text { Smartphones } \\
\text { Computers }\end{array}$ & $\begin{array}{l}209 \\
91\end{array}$ & $\begin{array}{l}69.7 \% \\
30.3 \%\end{array}$ \\
\hline
\end{tabular}

Table 2 Demographic characteristics of respondents 
This study had been focusing on Malaysian consumers especially in teenagers about their online purchase dissatisfaction. Based on the outcome of the survey, the majority of the respondent are female $(62.7 \%)$ compared to male which is only (37.3\%). Thus the respondents were not equally distributed between both genders as the female is majority. Next, the age of teenagers who responded to our survey are below 18 years old which is $(37.7 \%), 19$ to 22 years old (34.7\%) and 23 to 25 years old (27.7\%). After that, we also have the outcome for the race of the teenagers. Mostly teenagers are Malay with the percentage of (79.7\%), while Chinese (13.3\%) and Indian (7.0\%). The profession for our respondents are equally distributed between unemployed and employed with the percentage of (33.7\%) for unemployed and $(31.3 \%)$ for employed. While for students are $(35.0 \%)$. For the next question is about time spend on the internet per day is mostly teenagers used $1-5$ hours per day to surf the internet which is $(71.3 \%)$. While for $5-10$ hours is $(24.0 \%)$ and the least is more than 10 hours $(4.7 \%)$. The most common used tools for online purchasing are using smartphones which is (69.7\%) and by using computers are only (30.3\%).

\section{Use online purchasing per month}

In this part, we divide the frequency of online purchasing per month into 3 categories which is 1-3 times per month, 3-5 times per month, and above 5 times per month. Table 3 showed the number of frequencies of online purchaser to purchase in a month.

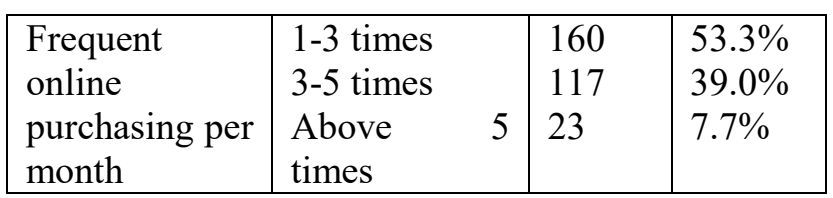

Table 3 frequent online purchasing per month

Based on the above table, there were 160 respondents who purchased online from 1-3 times per month with the percentage of $53.3 \%$. This is the highest number of respondents as they might not really purchased too frequent in the particular month. Next, is the number of frequency for respondents who purchased 3-5 times in a month is 117 with the percentage of $39.0 \%$. Lastly, is the frequency of online purchasers who purchased above 5 times in a month is 23 with the percentage of $7.7 \%$.

\section{FINDINGS AND CONCLUSION}

Initially analysis was performed by researchers using MATLAB [16-21], but at the same time non engg researchers just visualized their results using Excel or other way [22-25]. We have choosen second option but did not used visualization.

\section{Reliability Analysis}

Below is the table 4 that shows the Cronbach alpha and items of each independent variable namely quality of products, fraud and security, delivery and product's information. The Cronbach's coefficients alpha values for all factors that ranged from 0.705 to 0.739 indicated good inter-item consistency for each factor. Sekaran (1992) explained that the reliability of a measure is established by testing for consistency and stability of data collected.

\begin{tabular}{|l|l|l|l|l|}
\hline Variables & $\begin{array}{l}\text { Number } \\
\text { of items }\end{array}$ & $\begin{array}{l}\text { Items } \\
\text { dropped }\end{array}$ & $\begin{array}{l}\text { Items } \\
\text { recorded }\end{array}$ & $\begin{array}{l}\text { Cronbach } \\
\text { Alpha }\end{array}$ \\
\hline Fraud & 5 & - & - & 0.709 \\
\hline
\end{tabular}




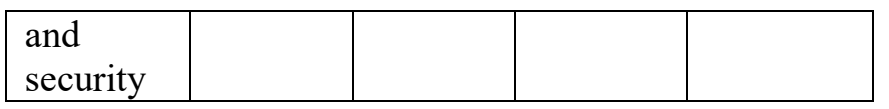

Table 4 Results of Reliability Test

Reliability analysis was used to measure the goodness of data. This is to ensure that all items used in each variables are free from error and thus, providing consistent results. According to Sekaran (2000), the range of alpha was measured by over 0.80 was considered good whereas range of 0.70 is considered acceptable.

\section{Descriptive Analysis}

Table 5 presents the means and standard deviation for all the study variables.

\begin{tabular}{|l|l|l|}
\hline Variables & Mean & $\begin{array}{l}\text { Standard } \\
\text { deviation }\end{array}$ \\
\hline $\begin{array}{l}\text { Fraud and } \\
\text { security }\end{array}$ & 3.4787 & 0.90140 \\
\hline
\end{tabular}

Table 5 Descriptive Analysis

By referring to the above table, this mean and standard deviation for independent variables measures which is product's information with mean of 3.6360 .

Factors Affecting Customers' Online Purchasing Dissatisfaction Among Teenagers.

Multiple regression analysis was used in order to determine the factors affecting customers' online purchasing dissatisfaction among teenagers.

\begin{tabular}{|l|l|l|l|}
\hline Variables & Beta & t-Ratio & Sig. t \\
\hline Fraud and security & -0.101 & -2.865 & 0.004 \\
\hline \multicolumn{3}{|c|}{ R square $=0.056$} \\
F $=4.379$ \\
Sig. F $=0.036$
\end{tabular}

Table 6 Results of Regression Analysis on Acceptance

The regression analysis indicates fraud and security was found to have significant at $5 \%$ significant level $(\mathrm{sig}, \mathrm{t}=0.004)$. This could explained that customers are more likely to take serious on fraud and security of the products they purchased. Besides, customers also are worried if their products are being scammed or their personal information are being stolen by some irresponsible party. The hypothesis $\mathrm{H} 2$ which stated that there is a relationship between fraud and security and factors affecting customers' online purchasing dissatisfaction among teenagers is substantiated.As a conclusion, The Malaysian Computer Emergency Response Team (MyCert) reported a total amount of 3,921 cases of online fraud (MyCert, 2016). The financial loss due to e-commerce fraud in Malaysia has been increasing from the year 2007 to 2012. Online business and consumers are vulnerable towards online fraud due to the increased amount of usage on online transactions. The study aims to investigate the factors that contribute towards online purchases from the experience of online fraud victims. Factors examined include trust, familiarity and awareness towards online products of which a semi structured interview was designed based on these factors. The qualitative study analyses experience of online fraud victims in order to gain insight to individual behaviour and determine the reason why they are induced in making the online purchase. The samples used in this study are the online fraud victims of E-commerce. Through seven phone interviews 
of online fraud victims, the study conclude that people with higher levels of familiarity, confidence and trust seems to have higher levels of trustworthiness to e-commerce. The awareness of the surroundings on the other hand does not affect people's inclination to purchase. The main contribution of this study is from an observation on cybercrime when globalisation of the Internet is rapidly moving forward.In order to increase the confidence among consumers about the perception on Internet security issues, the following are guidelines that our paper recommends ;Poor usage of passwords is another reason for security breaches. Users or staff in organizations may not use strong passwords because it is not easy to remember.IT and internet security roadshows and exhibitions to be extended to rural areas to educate the rural people.Consumers should be more proactive to know the sites they are visiting and be more cautious in giving personal or financial information and also take the effort to know the credibility of the organization they are dealing with.Self-regulation by the industry, since the laws in Malaysia and other parts of the world are quite vague, educate themselves as to how their personal data can be protected to understand consumer rights and deficiencies of the law.

\section{REFERENCES}

[1] Souca, M. L. (2014). Customer dissatisfaction and delight: completely different concepts, or part of a satisfaction continuum?.Management \& Marketing, 9(1).

[2] Chen, M. Y., \&Teng, C. I. (2013).A comprehensive model of the effects of online store image on purchase intention in an e-commerce environment. Electronic Commerce Research, 13(1), 1-23.

[3] Bruneel, C. A., Lakhdar, C. B., \&Vaillant, N. G. (2014). Are "legal highs" users satisfied? Evidence from online customer comments.Substance use \& misuse, 49(4), 364-373.

[4] Rashid, I. M. A., Abdullah, M. F. S., YUSUF, B. N. M., \& SHAARI, M. S. (2014). Impact of service and food quality on customer satisfaction among generation $\mathrm{Y}$ for the fast food restaurant in Malaysia. Journal of Social Science Research, 5(2), 784-793.

[5] Rashid, I. M. A., \&Razak, N. A. A. (2016).Determinants of Foreign Direct Investment (FDI) in Agriculture Sector Based on Selected High-income Developing Economies in OIC Countries: An Empirical Study on the Provincial Panel Data by Using Stata, 2003-2012.Procedia Economics and Finance, 39, 328-334.

[6] Arellano, M. and Bond, S. (1991).Some Test of Specification for Panel Data: Monte Carlo Evidence and Application to Employment Equation.Some Test of Specification for Panel Data: Monte Carlo Evidence and Application to Employment Equation.

[7] Kumari, J. (2014). Foreign Direct Investment and Economic Growth: A Literature Survey.BVIMSR's Journal of Management Research, 6(2), 118-127.

[8] Rashid, I. M. A., Rani, M. J. A., Yusuf, B. N. M., \&Shaari, M. S. (2015). The Impact Of Service Quality And Customer Satisfaction On Customer's Loyalty: Evidence From Fast Food Restaurant Of Malaysia. International Journal of Information, Business and Management, 7(4), 201.

[9] Samah, I. H. A., Shamsuddin, A. S., Abd Rashid, I. M., \&Amlus, M. H. Functional Organizational Structure And Employee Engagement In Malaysian Hotel Sector.

[10] Abdullah, M. F., Samah, I. H. A., Rashid, I. M. A., Kamaruddin, N. S., \&Radzi, W. N. W. M. (2018, October). Employee's Turnover Intention: A Case of Entrepreneurial Turnover Intentionsamong Employees in Malaysia. In ICRTEMMS Conference Proceedings (Vol. 489, No. 491, pp. 489491).SwarnaBharathilnstitute of Science and Technology

[11]Somasekar, J. \& Sharma, A. \& Reddy, N. \& Reddy, Y..(2020). IMAGE ANALYSIS FOR AUTOMATIC ENUMERATION OF RBC INFECTED WITH PLASMODIUM PARASITESIMPLICATIONS FOR MALARIA DIAGNOSIS.Advances in Mathematics: Scientific Journal. 9. 12211230. 10.37418/amsj.9.3.48.

[12] A. SHARMA1 AND J. SOMASEKAR"Contrast Image Construction Technique for Medical Imaging" published in Advances in Mathematics: Scientific Journal (Adv. Math., Sci. J.) vol-9-no-6-2020 (pp 3325-3329) 
[13]RohiniGoel, Avinash Sharma, and Rajiv Kapoor, "Object Recognition Using Deep Learning" published in Journal of Computational and Theoretical NanoscienceVol. 16, 4044-4052, 2019

[14] Santosh, Mamta\& Sharma, Avinash.(2019). A Proposed Framework for Emotion Recognition Using Canberra Distance Classifier.Journal of Computational and Theoretical Nanoscience.16. 3778-3782. 10.1166/jctn.2019.8250.

[15] MamtaSantosh, Avinash Sharma, "Facial Expression Recognition using Fusion of LBP and HoG Features" published in International Journal of Innovative Technology and Exploring Engineering (IJITEE) ISSN: 2278-3075, Volume-8 Issue-8 June, 2019.

[16]Varsha, N. Kumar, Energy Efficient TABU Optimization Routing Protocol for WSN,IngenieríaSolidaria, Universidad Cooperativa de Colombia, Issue- 33, July 2020.

[17] Muskan Jindal; EshanBajal; AlakanandaChakraborty; Prabhishek Singh, Ph.D; Manoj Diwakar; Neeraj Kumar, "A Novel Multi-Focus Image Fusion Paradigm: A Hybrid Approach", Materials Today: Proceedings,Elsevier, 2020.

[18]ManojDiwakar, AmrendraTripathi, Kapil Joshi, MinakshiMemoria , Prabhishek Singh, Neerajkumar, "Latest Trends on Heart Disease Prediction using Machine Learning and Image Fusion", Materials Today: Proceedings,Elsevier, 2020.

[19]ManojDiwakar; AmrendraTripathi; Kapil Joshi; Ayush Sharma; Prabhishek Singh; MinakshiMemoria; Neeraj Kumar, "A Comparative Review: Medical Image Fusion using SWT and DWT", Materials Today: Proceedings,Elsevier, 2020.

[20]ParthWadhwa; Aishwarya; AmrendraTripathi; Prabhishek Singh; Manoj Diwakar; Neeraj Kumar, "Predicting the Time Period of Extension of Lockdown due to Increase in Rate of COVID-19 Cases in India using Machine Learning", Materials Today: Proceedings Elsevier, 2020.

[21]Awadhesh Kumar Maurya,Varsha, Neeraj, Ajay Kumar, Neeraj Kumar, "Improved chain based cooperative routing protocol in wsn”, FEST, Journal of Physics: Conference series, IOP Publishing, $1478,1-8,13 / 05 / 2020$.

[22]V. Velvizhi; Satish R Billewar; GauravLondhe; PravinKshirsagar; Neeraj Kumar, "Big Data for Time Series and Trend Analysis of Poly Waste Management in India", Materials Today: Proceedings, Elsevier, 2020.

[23]N. Kumar, A. Agrawal,R. A. Khan, "METHWORK: An Approach for Ranking in Research Trends with a Case Study for IoET, Recent advances in Computer Science and Communication (formerly Recent Patents on Computer Science), 2019.

[24]. Kumar, Neeraj, AlkaAgrawal, and R. A. Khan. "Cost estimation of cellularly deployed IoT-enabled network for flood detection." Iran Journal of Computer Science, issue 2, no. 1 (2019), Springer Nature: 53-64.

[25] A. Kumar Maurya, G. Arora, A. Arora and N. Kumar, "Security Issues in Cloud based Infrastructure: A Review", Journal of advanced research in dynamic control systems, Vol. 10, 14 Special Issue, 2018. 